\title{
MEMBANGUN JARINGAN PC CLONING MENGGUNAKAN SOFTWARE WINCONNECT
}

\author{
Naufal Labib \\ 165100055 \\ Universitas Mitra Indonesia, Sistem Informasi \\ naufallabib.students@umitra.ac.id
}

\begin{abstract}
ABSTRAK
Dengan berkembangnya teknologi komunikasi dan informasi, telah memberi pengaruh yang signifikan bagi pengolahan data. Data dari satu terminal sumber dapat ditransfer ke terminal lain melalui media transmisi. Transfer data dengan menggunakan transmisi elektronik biasa disebut dengan istilah komunikasi data ( data communication ) Dari sinilah berkembang teknologi yang disebut sebagai jaringan komputer.

PC Cloning, merupakan suatu konsep jaringan komputer yang menekankan pada proses komputasi disisi server dan sisi client yang berkinerja seminimal mungkin. Dengan PC Cloning, sisi client yang memiliki spesifikasi rendah dapat menjalankan semua aplikasi yang diinstal di server tanpa harus menginstal aplikasi yang bersangkutan di sisi client.

Skripsi ini membahas langkah-langkah penginstalan PC Cloning seperti instalasi software, konfigurasi sistem dan penerapannya dengan menggunakan software pihak ketiga yaitu Winconnect.
\end{abstract}

Kata Kunci:Jaringan, PC Cloning, Software Winconnect. 


\section{A. PENDAhUluan}

Dengan berkembangnya teknologi komunikasi dan informasi, telah memberi pengaruh yang signifikan bagi pengolahan data. Data dari satu terminal sumber dapat ditransfer ke terminal lain melalui media transmisi. Transfer data dengan menggunakan transmisi elektronik biasa disebut dengan istilah komunikasi data ( data communication ) Dari sinilah berkembang teknologi yang disebut sebagai jaringan komputer.

Pada awalnya komputer pribadi ( stand alone ), menggunakan program sesuai dengan kebutuhan pengguna tanpa ada mekanisme komunikasi data antarkomputer. Seiring dengan adanya revolusi di bidang teknologi informasi, kini komputer dapat bekerja dalam sistem jaringan komunikasi baik jarak dekat maupun jarak jauh, seperti yang terimplementasikan dalam jaringan lokal maupun jaringan global

Sebuah komputer yang bekerja secara individual rnempunyai banyak kelemahan dan keterbatasan dalam kinerjanya. Jika kita ingin menggunakan perangkat tambahan maka perangkat tersebut harus terhubung dengan komputer yang bersangkutan. Misalnya kita ingin menghubungkan sebuah komputer dengan printer, plotter, ataupun scanner. Maka komputer lain tidak bisa menggunakan perangkat tersebut kecuali jika kita juga menghubungkannya dengan komputer yang bersangkutan. Dalam hal ini kita harus menyediakan sejumlah perangkat tambahan sesuai dengan jumlah komputer yang akan mengolahnya. Begitu pula dengan data yang tersimpan di dalamnya Kita tidak bisa menggunakan data tersebut dengan komputer yang berbeda.Untuk mengatasi masalah ini adalah dengan menghubungkan satu komputer dengan komputer yang lain, agar setiap sumber daya yang terhubung di dalamnya dapat digunakan secara bersama-sama. Inilah yang disebut dengan istilah : Sistem Jaringan Komputer (Computer Networking System\}. 
Dengan terhubung ke sistem jaringan, komputer yang satu dapat mengakses data di komputer yang lain, dapat mencetak pada printer komputer lain, dapat mengirimkan info atau data ke komputer lain.

Kesemua hal tersebut diatas sangat erat kaitannya dengan perkembangan software juga. Perkembagan software aplikasi yang begitu dahsyatnya terkadang sulit diikuti. Alasan yang paling sering muncul adalah terbatasnya kemampuan hardware yang dimiliki. Software - software terbaru selalu menuntut kemampuan hardware yang lebih dari hardware yang telah ada. Bagi mereka yang memiliki cukup investasi masalah tersebut sudah cukup teratasi.

Komputer dengan teknologi terbaru membutuhkan biaya yang tidak sedikit. Bayangkan saja bila ada pekerjaan dalam jaringan yang membutuhkan upgrade komputer secara bersamaan. Tentunya membutuhkan biaya yang tidak sedikit. Namun bagaimana pula bagi mereka yang terbatas investasinya dan bekerja dalam jaringan pula?

Latar belakang inilah yang membuat penulis merasa tertarik untuk mengangkat judul "Membangun Jaringan PC Cloning Menggunakan Software Winconnect" sehingga dapat membantu mereka yang memiliki investasi terbatas namun tetap ingin menggunakan software terbaru. Jaringan komputer dengan sistem PC Cloning adalah solusi dari masalah ini. 


\section{B. TINJAUAN PUSTAKA}

Dalam suatu penetian diperlukan dukungan hasil-hasil penetian yang telah ada sebelumnya yang berkiatan dengan penetian tersebut.

PUTRA, Arie Setya; FEBRIANI, Ochi Marshella. Knowledge Management Online Application in PDAM Lampung Province. In: Prosiding International conference on Information Technology and Business (ICITB). 2018. P. 181-187.

Microsoft, Remote Desktop Protocol,www.microsoft.com/downloads/details.aspx? FamilyID =a8255ffc-4b4a-40e7-a706-cde7e9b57e79\&DisplayLang=en

Neibauer, Alan, Membuat Jaringan Komputer Untuk Perusahaan Kecil, Penerbit PT. Elex Media Komputindo, Jakarta 2003. 


\section{STUDI KASUS}

Jaringan komputer sebenarnya mencakup masalah yang sangat luas apalagi berhubungan dengan PC Cloning. Walaupun demikian penulis akan membatasi ruang lingkup yang spesifik saja, maka dalam pembahasan penulis akan memperkenalkan apa itu PC cloning dan juga penerapan aplikasi PC Cloning berbasis Winconnect menggunakan Windows XP sebagai server dan Windows 98 sebagai client. Untuk peneltiannya penulis menggunakan sebuah server Pentium 4 dengan OS Windows XP dan 2 buah client Pentium 100 dengan OS Windows 98.

Sistem ini dirancang dengan sesederhana mungkin untuk mempermudahkan pengguna dalam pengimplementasiannya. 


\section{DISKUSI}

\section{Pengertian PC Cloning}

Membangun sustu sistem jaringan kini bukanlah hal yang sulit. Permasalahannya sekarang adalah bagaimana sistem jaringan yang kita bangun tersebut dapat seimbang kinerjanya antara server dan client agar dapat diperoleh unjuk kerja yang optimal, dan ini berhubungan dengan biaya yang relatif mahal. Apalagi pada saat krisis seperti saat sekarang ini, dimana nilai tukar rupiah terhadap dolar masih tinggi.

Secara ideal, komputer-komputer yang terintegrasi dalam sebuah jaringan adalah komputer yang berprocesor minimal Intel Pentium 233 MMX ( atau yang sejenisnya ) terlebih lagi yang dipersiapkan untuk server haruslah komputer dengan spesifikasi yang tinggi ( misalnya Intel Pentium 4 ). Akan tetapi untuk menyediakan komputer dengan spesifikasi seperti itu masih dirasakan relatif berat. Oleh karena itu, diperlukan alternatif solusi untuk menanggulangi permasalahan dana bagi pembangunan sebuah sistem jaringan.

Disinilah istilah mengkloning komputer atau lebih populernya disebut PC Cloning System muncul sebagai jawaban atas permasalahan tersebut. Mengkloning komputer bukan berarti menduplikasi sebuah komputer menjadi dua buah atau lebih. Seperti halnya seorang ilmuwan yang telah berhasil mengkloning seekor domba memjadi dua ekor yang sama persis. Akan tetapi istilah "cloning" disini digunakan untuk menyebut proses transfer kemampuan hardware dari server ke clientnya. Jadi yang diduplikasikan bukanlah komputer secara fisik, tetapi hardware server diduplikasi ( baca: dikloning ) ke semua client yang terkoneksi.

\section{Keuntungan Penerapan PC Cloning System}

Dengan penerapan sistem ini diharapkan akan memberikan nilai lebih kepada sistem jaringan komputer yang dibangun, berupa :

- Menghemat kebutuhan hardware dan Software 
Bayangkan kalau misalnya kita harus menyediakan sekian unit komputer yang up to date untuk membangun sebuah jaringan. Bisa ditebak, pastilah membutuhkan hardware dan juga software yang tidak sedikit. Hal ini bisa diatasi dengan penerapan PC Cloning System. Singkatnya, kita cukup memilikI 1 unit komputer server dengan spesifikasi yang up to date, contohnya dengan menggunakan processor Pentium 4, sedangkan clientnya bisa memamfaatkan processor x86 saja. Kemudian komputer server yang berprosesor Pentium 4 tersebut akan mengclone dirinya ke daiam client yang terkoneksi sehingga komputer client yang hanya berprocessor x 86 kinerjanya menjadi relatif setara dengan server yang berprocecor Pentium 4 dan dapat menjalankan semua aplikasi yang terinstal di dalam server.

- Menghemat investasi.

Dengan menghemat kebutuhan hardware dan software komputer, otomatis akan menghemat pula investasi yang dikeluarkan untuk membangun sebuah sistem jaringan komputer. 


\section{E. KESIMPULAN}

1. Software-software yang digunakan dan langkah-langkah penginstalan sudah berbasiskan sistem operasi windows sehingga memudahkan siapa saja yang akan mempraktekkannya.

2. Jaringan ini dapat dikembangkan pada perkantoran, warnet, laboratorium komputer, kantor pemerintah dan swasta

3. Dengan menggunakan PC Cloning biaya untuk pengadaan komputer dapat ditekan sehingga dapat dialokasikan untuk keperluan lain seperti UPS sebagai backup listrik dimana seperti kita ketahui bersama keadaan listrik saat sekarangt ini tidak stabil

4. Untuk mempelajari dan mempraktekkan ilmu jaringan pc cloning tidaklah sesulit yang penulis kira karena pengetahuan dasar mengenai teknik jaringan ini sudah penulis pelajari pada mata kuliah komunikasi data dan jaringan. 


\section{F. REFERENSI}

[1] PUTRA, Arie Setya; FEBRIANI, Ochi Marshella. Knowledge Management Online Application in PDAM Lampung Province. In: Prosiding International conference on Information Technology and Business (ICITB). 2018. P. 181-187.

[2] FEBRIANI, Ochi Marshella; PUTRA, Arie Setya. Sistem Informasi Monitoring Inventori Barang Pada Balai Riset Standardisasi Industri Bandar Lampung. Jurnal Informatika, 2014, 13.1: 90-98

[3] Putra, A. S. (2018, July 9). 2018 Artikel Struktur Data , Audit dan Jaringan Komputer. Retrieved from osf.io/3uq8w

[4] Harry Prihanto, Membangun Jaringan Komputer, Ilmukomputer.com Juni 2003

[5] Lisal Faisal, Menghemat Dengan Membangun Jaringan PC Cloning Menggunakan Winconnect, Ilmukomputer.com Juni 2006

[6] Mudji Basuki, Network Address Translation ( NAT ), Ilmukomputer.com Mei 2004 